\title{
Commentary
}

The article presented by Netto et al. is a case of pseudohypertrophy of the entire right lower extremity due to a neurogenic etiology ${ }^{[1]}$ However, it is important for the readers to realize that there are also similar cases reported in the literature that result in neurogenic atrophy. ${ }^{[2-4]}$ Although diagnostic modalities such as EMG and imaging direct the readers to a S1 radiculopathy secondary to a sacral lipoma (manifested clinically in the distal musculature), there are likely other etiologies to explain the pseudohypertrophy witnessed in the right proximal musculature. A combination of tethered cord and radiculopathy better explains the underlying etiology. The principal etiology of tethered cord syndrome has been demonstrated to be mainly secondary to the longitudinal traction of the caudal end of the spinal cord..$^{[3,4-6]}$ A sacral lipoma can be a contributing factor to a tethered cord syndrome. The pathophysiology of the neurologic deficits seen is caused by the effect of spinal cord tethering or compression produced by the presence of a lipoma. In animal models, it has been illustrated that this mechanical pull leads to changes in blood flow and to hypoxemia, with resultant reduction in oxidative metabolism that can clinically manifest as neurologic deficits. ${ }^{[4]}$ The natural history of the spinal lipoma is poorly defined, and surgical management of this lesion can be controversial. ${ }^{[7]}$

\section{Kevin Kohan}

Department of Anesthesiology, Pain Medicine Fellow, UC Health University Hospital, University of Cincinnati, Clinical Instructor, 234 Goodman Dr., Cincinnati, OH 45219, USA

\author{
Address for correspondence: \\ Dr. Kevin Kohan, \\ Department of Anesthesiology, \\ Pain Medicine Fellow, \\ UC Health University Hospital, \\ University of Cincinnati, \\ Clinical Instructor, 234 Goodman \\ Dr., Cincinnati, OH 45219, USA. \\ E-mail: kohankn@ucmail.uc.edu
}

\section{References}

1. Netto AB, Sinha S, Taly AB, Prasad C, Mahadevan A, Bindu PS, et al. An unusual case of unilateral limb hypertrophy: Lipoma of sacral roots. J Neurosci Rural Pract 2012;3:89-92.

2. Matsuuoka T, Ueyama H, Ando Y, Kumamoto T, Araki S. A case of adult-onset tethered cord syndrome accompanied with slowly progressive muscular atrophy in the lower limbs. Rinsho Shinkeigaku 1991;31:778-80.

3. Wakata N, Araki Y, Murabayashi K, Fujioka T, Nishina M, Kinoshita M. Tethered cord syndrome accompanied by unilateral muscle atrophy in calf muscle. Intern Med 1994;33:60-3.

4. Kohan KJ, Lee SW. Adult onset tethered cord syndrome presenting with unilateral calf atrophy. PM R 2010;2:676-80.

5. Yamada S, Zinke DE, Sanders DC. Pathophysiology of "tethered cord syndrome." J Neurosurg 1981;54:494-503.

6. Tani S, Yamada S, Knighton RS. Extensibility of the lumbar and sacral cord. Pathophysiology of the tethered cord in cats. J Neurosurg 1987;66:116-23.

7. Aufschnaiter K, Fellner F, Wurm G. Surgery in adult onset tethered cord syndrome (ATCS): Review of literature on occasion of an exceptional case. Neurosurg Rev 2008;31:371-84.

\begin{tabular}{|l|l|}
\hline \multicolumn{2}{|c|}{ Access this article online } \\
\hline Quick Response Code: & \\
\hline & Website: \\
\hline & \\
\hline
\end{tabular}

